\title{
Mapping and validating predictions of soil bacterial biodiversity using European and national scale datasets
}

Article

Accepted Version

Creative Commons: Attribution-Noncommercial-No Derivative Works 4.0

Griffiths, R. I., Thomson, B. C., Plassart, P., Gweon, H. S., Stone, D., Creamer, R. E., Lemanceau, P. and Bailey, M. J. (2016) Mapping and validating predictions of soil bacterial biodiversity using European and national scale datasets. Applied Soil Ecology, 97. p. 61. ISSN 0929-1393 doi: https://doi.org/10.1016/j.apsoil.2015.06.018 Available at https://centaur.reading.ac.uk/75774/

It is advisable to refer to the publisher's version if you intend to cite from the work. See Guidance on citing.

Published version at: https://doi.org/10.1016/j. apsoil.2015.06.018

To link to this article DOI: http://dx.doi.org/10.1016/j.apsoil.2015.06.018

Publisher: Elsevier

All outputs in CentAUR are protected by Intellectual Property Rights law, including copyright law. Copyright and IPR is retained by the creators or other copyright holders. Terms and conditions for use of this material are defined in the End User Agreement. 


\section{CentAUR}

Central Archive at the University of Reading

Reading's research outputs online 
1 Mapping and validating predictions of bacterial biodiversity using European and 2 national scale datasets

4 Robert I. Griffiths ${ }^{1}$, Bruce C. Thomson ${ }^{1}$, Pierre Plassart ${ }^{2}$, Hyun S Gweon ${ }^{1}$, Dorothy Stone ${ }^{3}$, $5 \quad$ Rachael E. Creamer ${ }^{3}$, Philippe Lemanceau ${ }^{4}$, Mark J Bailey ${ }^{1}$

6

$7 \quad{ }^{1}$ Centre for Ecology and Hydrology, Maclean Building, Benson Lane, Crowmarsh Gifford, 8 Wallingford, UK

$9 \quad$ 2INRA, UMR1347 Agroécologie, GenoSol Platform, Dijon, France

${ }^{3}$ Teagasc, Johnstown Castle Research Centre, Co. Wexford, Ireland

${ }^{4}$ INRA, UMR1347 Agroécologie, Dijon, France

12

Corresponding author: R.I.G (email: rig@ceh.ac.uk) 


\section{Abstract}

Recent research has highlighted strong correlations between soil edaphic parameters and bacterial biodiversity. Here we seek to explore these relationships across the European Union member states with respect to mapping bacterial biodiversity at the continental scale. As part of the EU FP7 EcoFINDERs project, bacterial communities from 76 soil samples taken across Europe were assessed from eleven countries encompassing Arctic to Southern Mediterranean climes, representing a diverse range of soil types and land uses (grassland, forest and arable land). We found predictable relationships between community biodiversity (ordination site scores) and land use factors as well as soil properties such as $\mathrm{pH}$. Based on the modelled relationship between soil $\mathrm{pH}$ and bacterial biodiversity found for the surveyed soils, we were able to predict biodiversity in $\sim 1000$ soils for which soil $\mathrm{pH}$ data had been collected as part of national scale monitoring. We then performed interpolative mapping utilising existing EU wide soil $\mathrm{pH}$ data to present the first map of bacterial biodiversity across the EU member states. The predictive accuracy of the map was assessed again using the national scale data, but this time contrasting the EU wide spatial predictions with point data on bacterial communities. Generally the maps were useful at predicting broad extremes of biodiversity reflective of low or high $\mathrm{pH}$ soils, though predictive accuracy was limited for Britain particularly for organic/acidic soil communities. Spatial accuracy could however be increased by utilising published maps of soil $\mathrm{pH}$ calculated using geostatistical approaches at both global and national scales. These findings will contribute to wider efforts to predict and understand the spatial distribution of soil biodiversity at global scales. Further work should focus on enhancing the predictive power of such maps, by harmonising global datasets on soil conditioning parameters, soil properties and biodiversity; and the continued efforts to advance the geostatistical modelling of specific components of soil biodiversity at local to global scales.

\section{Introduction}


Soil bacteria contribute the largest proportion of the soil genetic resource (Urich et al 2008; Fierer et al, 2012), reflecting their ubiquity and high abundance across all soil systems. Given bacterial importance in the regulation of soil ecosystem services (Comerford et al, 2013), increased understanding of the environmental controls of bacterial biodiversity is required from both scientific and policy perspectives in order to predict biodiversity change, and determine functional consequences of change due to future climatic or land use pressures. Attempts to characterise the bacterial communities in soils and understand ecological drivers have previously been hampered by methodological difficulties in assessing taxonomic diversity due to the limited culturability of many bacterial taxa coupled with vast taxonomic diversity (e.g Janssen et al, 2002). These problems have to some extent been overcome through the development of molecular technologies to assess the diversity of taxonomic marker genes (particularly the 16S rRNA gene) PCR amplified from extracted soil DNA (Hirsch et al, 2010).

The application of molecular methods to wide ranging globally dispersed soil samples has revealed that soil bacterial communities are broadly structured along gradients of soil properties, with strong correlations between measures of bacterial biodiversity and key soil variables such as soil $\mathrm{pH}$ and organic matter, which are co-related with broader environmental parameters such as land use, climate, and parent material (Fierer et al, 2006; Lauber et al, 2009; Griffiths et al 2011). Therefore, whilst the causal mechanisms underlying these relationships are complex it is apparent that the same pedogenic factors which determine the nature of soils (e.g Jenny, 1941) also determine the taxonomic characteristics and structure of the soil bacterial community. This new knowledge permits spatial forecasting of bacterial biodiversity at a range of scales and under change scenarios; which together with parallel developments in understanding microbial biodiversity-function relationships, may allow for enhanced prediction of soil processes under future environmental change. 
Molecular surveys permit the production of range maps of soil bacterial distributions

at various spatial scales. Spatial distribution maps provide a visual representation of the forces shaping populations or communities and therefore provide the foundation for macro ecological understanding (Elton, 1927). Maps can also guide policy decisions with respect to land management, and can be useful visual resources guiding scientific experimentation and enquiry. Importantly, more recently rasterised maps provide georeferenced data which can feed wider ecological, climatic or biogeochemical models. Already there has been several attempts to map soil microbial properties at national and regional scales, using molecular methodologies applied to nationwide soil monitoring schemes (Bru et al, 2011; Griffiths et al 2011, Dequidet et al 2009; Dequidet et al 2011). These studies mapped point sampled microbial data using interpolative methods (e.g inverse distance weighting, kriging; see Bivand et al; 2008) to fit surfaces predicting the microbial properties at unsampled locations by weighted averages of surrounding measured values. These methods are useful to show large differences in microbial properties over large areas but local accuracy is limited by the spatial scale of sampling.

More advanced geostatistical approaches can be used to predict a variable of interest at unsampled locations based on known relationships between the dependant variable and other predictor variables (e.g climate, soil type, land cover). Such approaches are commonly used in wider ecology (sometimes termed environmental-, ecological-, or species- distribution modelling: Elith et al, 2006), and can be used to predict either species or communities at unsampled locations (Chapman and Purse, 2011). These environmental correlational approaches have so far been used to predict historical change in soil bacterial biodiversity due to land use at regional scales (Fierer et al, 2013); and also to improve on the interpolated maps of bacterial biodiversity across Great Britain (Griffiths et al, 2011) by modelling the observed relationships between bacterial communities and environmental variables, and then forecasting communities in unsampled locations using remote sensed land cover information 
and parent material maps (Henrys et al, 2015). This paper aside there are few studies which have examined in detail the predictive performance of such maps compared to simple interpolation. More widely, large scale spatial predictions of soil parameters are increasingly being disseminated through downloadable map resources (e.g soilgrids.org, ukso.org), and there is now a need to identify specific predictive limitations in order to further improve accuracy (Hengl et al, 2014).

Here as part of this special issue reporting results from the EU FP7 EcoFINDERs project coordinated soil sampling campaign, we seek to assess the bacterial communities in 76 soils sampled across Europe in order to produce a soil bacterial map at the European scale, which can be validated against national scale datasets. We predict that soil $\mathrm{pH}$ will be the strongest correlate with measures of community biodiversity, which will then allow us to predict and spatially interpolate communities based on publicly available European scale point data on soil pH (from the LUCAS survey: Tóth et al, 2013). The predictive accuracy of this map will be assessed by comparing predictions with observed point data on bacterial communities collected with similar methods from over 1000 soils across Great Britain (Griffiths et al, 2011). We will also explore whether the predictions from this simple interpolated map can be improved upon, by spatially predicting communities based on existing soil $\mathrm{pH}$ maps produced using more advanced environmental correlation approaches (from soilgrids.org and ukso.org).

\section{Materials and Methods}

\subsection{Sampling}

Bacterial communities were examined in soils sampled across the EU member states as part of the EcoFINDERs project "transect" sampling campaign, full details of which are prodived elsewhere in this issue (Stone et al, 2015). Briefly, a range of sites spanning a gradient of soil properties (principally $\mathrm{pH}$, organic matter and texture), climatic zones, and 
land uses (grassland, arable, forest) were targeted for sampling following examination of EU wide datasets (see supplementary material for site locations, S1). Samples were collected at the end of summer 2012 according to standardised protocols to $5 \mathrm{~cm}$ depth, and sent to a central processing lab for homogenisation and distributing to various partner labs for further analyses. In total eighty-two soils from 11 countries encompassing Arctic to Southern Mediterranean climes of which 76 are assessed in this study. Soil chemical determinations were also conducted by a single laboratory to provide measures of volumetric moisture content, $\mathrm{pH}$ (in water), texture, and total/organic carbon $(\mathrm{C})$ and nitrogen $(\mathrm{N})$ contents.

\subsection{DNA extraction and community analyses}

Total genomic DNA was extracted from all soil samples using a previously described DNA extraction procedure (Plassart et al., 2012). Briefly, $1 \mathrm{~g}$ of soil was mixed at $70^{\circ} \mathrm{C}$ with a extraction buffer containing $100 \mathrm{mM}$ Tris- $\mathrm{HCl}(\mathrm{pH}$ 8), $100 \mathrm{mM}$ EDTA (pH8), $100 \mathrm{mM} \mathrm{NaCl}$, $2 \%(\mathrm{w} / \mathrm{v})$ polyvinylpyrrolidone $(40 \mathrm{~g} \mathrm{~mol}-1)$ and $2 \%(\mathrm{w} / \mathrm{v})$ sodium dodecyl sulphate. Proteins were precipitated from the supernatant with $1 / 10$ volume of $3 \mathrm{M}$ sodium acetate, before nucleic acid precipitation with isopropanol. DNA was further purified through polyvinylpolypyrrolidone (PVPP) Microbiospin minicolumns (BIORAD, Marnes-la-Coquette, France) and finally using the Geneclean Turbo kit (MP-Biomedicals, NY, USA).

Bacterial communities were examined using TRFLP as described by Griffiths et al (2011) using the forward primer 63F (5'-CAGGCCTAACACATGCAAGTC-3') labelled at the 5' end with D4 blue fluorescent dye and reverse primer 530R (5'-GTA TTA CCGCGG CTG CTG-3'). Amplifications were performed in $50 \mu \mathrm{l}$ reactions under the following conditions: $94^{\circ} \mathrm{C}$ for $90 \mathrm{~s}$, followed by 35 cycles of $94^{\circ} \mathrm{C}$ for $45 \mathrm{~s}, 55^{\circ} \mathrm{C}$ for $1 \mathrm{~min}$ and $72^{\circ} \mathrm{C}$ for $3 \mathrm{~min}$, followed by a final extension of $72^{\circ} \mathrm{C}$ for $10 \mathrm{~min}$. Amplicons were then purified using the ZR96 DNA clean-up kit (Zymo research, Freiburg, Germany), prior to enzymatic digestion. Purified bacterial DNA was digested with Mspl restriction enzyme (New England Biolabs Inc., Ipswich, MA, USA) at $37^{\circ} \mathrm{C}$ for $3 \mathrm{~h}$. Fragment analysis was performed with a Beckman Coulter 
CEQ 2000XL capillary sequencer (Beckman Coulter Corporation, California, USA). Peak height data were analysed using GeneMarker software (Softgenetics, LLC, PA, USA). Relative abundances were calculated as the ratio between the fluorescence of each terminal restriction fragment (T-RF) and the total integrated fluorescence of all T-RFs.

\subsection{Statistical Analyses}

A site by taxon (TRF) relative abundance table derived from the TRFLP analyses was used to explore community relationships with environmental variables, and calculate community scores (ordination site scores and diversity estimates) using standard routines in the vegan library within the R package (R Core Development Team, 2005). Geostatistical calculations, manipulations and plots were also performed within $\mathrm{R}$ using the maptools, gstat, raster, and RColorBrewer libraries. Specifically, to produce the bacterial map we used the inverse distance distance weighted (IDW) interpolation method, on account of it's simplicity and widespread application (Lam, 1983). The IDW method predicts a value at an unsampled location based on the weighted average of values at sampled point locations, with weights decreasing linearly with distance from that location. We used the idw function of the R library gstat to perform the interpolation, using leave one out cross validation to establish the optimum power parameter value (determining how much the weightings decrease with distance) and evaluate the overall performance of the interpolation with respect to predictive power. For both the IDW interpolative mapping, and the prediction contrasts with observed data from a national scale dataset, predictive power was evaluated by assessing the coefficient of determination (R2) and root mean square error (RMSE) between observed and predicted values.

\section{Results and Discussion}

\subsection{Continental scale patterns of soil microbial communities}


NMDS ordinations revealed distinct clustering of sampled communities according to

land use type (Figure 1). This was further confirmed following multivariate permutation tests using the anosim statistic $(R=0.28, P=0.0001)$. Pairwise comparisons further revealed that bacterial communities in forest soils were most distinct from to arable and grass communities $(R=0.54$, and $R=0.41$ respectively, $p<0.0001)$ with the largest differences in community structure consistently observed between forest and arable soils. Arable and grass communities were more similar, yet significant differences were still apparent despite the wide dispersion at the continental scale of sampling units $(R=0.08, p<0.05)$. Bacterial communities were found to differ between countries $(R=0.13, P<0.01)$. However, this effect could be predominantly attributed to the Swedish soil communities which were all sampled from forest sites and formed a distinct outgroup in the ordination (Figure 1b). When Swedish samples were excluded country of origin had no significant effect (bacteria $R=0.001, P=0.46$ ).

Fitting of environmental variables to the ordination scores also confirmed that microbial communities sampled across Europe were strongly correlated with environmental gradients. The dominant five environmental conditions most strongly associated with microbial community structure differences are presented in Table 1. Generally, bacterial community differences were highly correlated with change in soil chemistry and nutrient status, with soil $\mathrm{pH}$ showing the strongest relationship, confirming that across large spatial scales the structuring of soil bacterial communities is largely predictable by common soil physicochemical parameters.

These findings further highlight the difficulty in separating direct effects of land use on soil biota versus indirect effects, mediated by changes in soil abiotic properties. It is becoming increasingly apparent that none of these parameters are independent. Human land use is generally influenced by the local pedo-climatic context which determines the economic suitability of different land management options. The baseline pedo-climatic state will naturally create topsoils of distinct properties, which can be further modified by land use depending on 
the specific intervention. Different land uses are therefore often accompanied by distinct abiotic soil properties and consequently bacterial biodiversity, given the strong relationships between edaphic properties and soil bacterial communities. For instance, Scandinavian regions are characterised by cold conditions and acidic soils giving rise to more forest and less arable suitability. This in itself does not mean that soil bacterial communities are inherently geographically structured, nor that they are fundamentally driven by the land use of forestry, but is more a reflection of the natural pedo-climatic state which determines both the human land use and the soil biotic and abiotic properties. With respect to contrasts between arable and grassland habitats; whilst arable soils are generally defined by a relatively narrower set of soil properties (e.g high $\mathrm{pH}$ and low organic matter) it is possible for grasslands to possess similar properties, particularly if the grassland is part of a arable rotation. Such historical data is not available in this study and such specific contrasts are better addressed in locally focused long term experimental contrasts.

\subsection{Predictability and mapping of soil bacterial communities}

The site scores for bacterial communities were clearly strongly aligned along the first axis of the NMDS ordination which corresponds with a gradient of soil $\mathrm{pH}$. This afforded the opportunity to extrapolate and predict communities over larger spatial scales using wider soil $\mathrm{pH}$ datasets. Such datasets are available across $23 \mathrm{EU}$ member states from the LUCAS topsoil survey (Toth et al, 2013), which provides data on the percentage of coarse fragments, particle size distribution, $\mathrm{pH}$, organic carbon, carbonate content, phosphorous content, total nitrogen content, extractable potassium content, cation exchange capacity and multispectral properties from approximately 20000 soils. We therefore sought to model the relationships between soil $\mathrm{pH}$ and bacterial communities from the present survey, and then predict community NMDS scores for the 20000 data points across the $\mathrm{EU}$ of soil $\mathrm{pH}$ to enable the production of EU wide maps of predicted soil biodiversity using simple interpolative approaches. 
NMDS scores. Figure 2 shows the relationship observed between soil $\mathrm{pH}$ and the first axis bacterial community NMDS scores for the 76 soils assessed in this study. The relationship was visually assessed to be curvilinear and could be modelled with a simple second-degree polynomial $\left(R^{2}=0.93\right)$ of the equation:

To test the predictive power of the regression equation, we predicted the bacterial community NMDS axis 1 scores from a nationwide survey of over 1000 point measurements conducted across Great Britain using only the measured $\mathrm{pH}$ values as predictors (countrysidesurvey.org.uk/). Uniquely, this dataset also comprises bacterial TRFLP profiles (Griffiths et al 2011) therefore allowing us to independently test the predictive power of the regression equation on a different dataset. Despite several differences in methodologies (soil sampling depth, DNA extraction, taxonomic binning) the modelled relationships between soil $\mathrm{pH}$ and bacterial community ordination scores from less than 100 soils across Europe provided a reasonable prediction of the bacterial scores in over 1000 soils across Britain (Figure 3). It is noteworthy that the ordination axis scores are themselves arbitrary, and only denote the (dis)similarity between samples analysed at any one time. This fact makes the strong correlations between the EU wide and national scale datasets all the remarkable, and is perhaps testament to the strength and global ubiquity of the relationships between soil $\mathrm{pH}$ and bacterial communities, provided a sufficient range of soils are sampled.

To map bacterial communities across the EU member states we then predicted the NMDS axis 1 ordination scores for the $\sim 20000$ soils sampled in the LUCAS survey based on $\mathrm{pH}$ measurements and the equation outlined above. The LUCAS datasets were downloaded subject to agreements from the JRC European Soil Portal (http://eusoils.jrc.ec.europa.eu/) and a map showing the sampled locations is provided in the supplementary material (S2).

255 Predicted community scores were then mapped using inverse distance weighting 
interpolation. We firstly compared interpolative performance using different integer powers parameters (1-5), and the accuracy of predictions assessed by comparing the deviation from the measured data using a leave one out cross-validation procedure. The best performing interpolated map is shown in Figure 4. This was made using an IDW power parameter of 2 which yielded the lowest root mean square error (RMSE) for predicting bacterial NMDS1 scores $(0.28)$, together with the highest precision with respect to the relationship between observed and predicted values $\left(R^{2}=0.58\right)$.

\subsection{Features of the map}

The map reveals the broad types of bacterial communities found across Europe based on the strong relationships between soil bacterial biodiversity and soil $\mathrm{pH}$. The low (negative) NMDS axis 1 scores reflect communities found in areas such as Scandinavia where acidic and organic rich soils develop due to climatic factors; whereas high values indicate communities found in more productive Southern circum-neutral $\mathrm{pH}$ soils, typically with lower organic matter. Areas of contrasting local variability can also be seen in certain regions, where geological factors such as differences in underlying parent material or topography cause local change in communities.

To taxonomically interpret the features of the map we must firstly consider the "meaning" of the first axis ordination scores. The axis 1 ordination scores summarise differences in the broad taxonomic composition and relative abundance of taxa between samples. Additionally, in this study, the scores correlated positively with indices of diversity (Figure 5), with lower scores reflecting low taxonomic diversity. The specific change in abundance of different bacterial taxa across soil pH/diversity gradients has been well studied using sequencing (e.g see Lauber et al 2009; Rousk et al 2010; Griffiths et al, 2011) and can also be inferred to some extent from TRFLP analyses (some illustrative responses of dominant TRFLP peaks are shown the supplementary material, S3). To summarise these responses briefly, acidic and organic rich soils are notably dominated by distinct lineages of 
acidophilic acidobacteria, as well as alphaproteobacterial taxa. As $\mathrm{pH}$ increases over soil environmental gradients, the alphaproteobacteria become dominant, followed by other broad taxonomic groups such as other proteobacteria and the actinobacteria as $\mathrm{pH}$ nears neutrality.

Neutral soils typically comprise a wider variety of different bacterial taxonomic groups of higher evenness (Griffiths et al, 2011); a phenomena which is at odds with the notion that agricultural soils (often neutral $\mathrm{pH}$ ) are depauperate with respect to biodiversity (Spurgeon et al, 2013). Potential explanations for higher soil bacterial biodiversity in agricultural soils could be: i) more bacterial taxa exist at neutral $\mathrm{pH}$, due to the requirements of intracellular $\mathrm{pH}$ homeostasis (Booth, 1985); ii) soil physical properties in mineral agricultural soils provide more microhabitats promoting evenness (e.g spatial isolation theories, Zhou et al, 2002); and (iii) mineral agricultural soils have less active populations meaning a high diversity of sensescent cells, or even extracellular DNA are being detected. We note also that several studies have reported increased dominance of certain lineages, despite higher phylogenetic diversity, in neutral soils resulting in declines in indices of diversity at higher $\mathrm{pH}$ (e.g Fierer et al, 2006). This is apparent to some extent in certain arable and grassland soils in Figure 5 which appear to have a marked dominance of alphaproteobacterial TRF peaks, though the underlying causes of this have yet to be fully elucidated. Given the importance of these soils for agricultural production together with recent concerns over soil and food security, the specific controls of neutral-soil taxon abundances, and functional consequences of alterations in abundance, represents a key current knowledge gap.

\subsection{Map validation and contrasts with other mapping approaches}

In order to assess the accuracy of the EU bacterial map wide we contrasted the spatial predictions with observed national scale data from the British Survey. The interpolated map was firstly converted to a raster, and then the predicted NMDS1 scores extracted using the sample locations of the British dataset, prior to correlation with the observed scores (figure 
6a). Despite a lack of a good linear fit and a tendency for the spatial predictions to cluster near the overall mean, the interpolation performed reasonably well at predicting the NMDS community scores across Britain (RMSE $\left.=0.41, R^{2}=0.29\right)$. Despite a lack of strong correlative relationships for lower $\mathrm{pH}$ communities, there was evidence that higher scoring (higher $\mathrm{pH}$ ) community scores could be predicted to some extent. This map of bacterial biodiversity therefore gives a very broad overview of the extreme types of communities likely to be found in different geographic locations across Europe, but for Britain it is of limited use in spatially predicting more subtle differences in communities. Its predictive power is limited by its reliance on the locations of the sampled LUCAS topsoil data points, the design of which has an inherent bias towards agricultural lands (Toth et al 2013). Few samples were taken from large areas of Scottish uplands in the LUCAS survey which may be explain the poor relationships between predicted and observed community scores across Britain. The lack of comparable national scale "test" datasets comprising bacterial data, means we are unable to assess the predictive accuracy of the map for other countries.

To assess whether the predictive accuracy could be enhanced by drawing on more advanced geostatistical predictions of soil $\mathrm{pH}$, we next applied the $\mathrm{pH}$-biodiversity transfer function to two existing soil $\mathrm{pH}$ maps: a recently published predictive map at the global scale (SoilGrids: soilgrids.org, Hengl et al 2014) and freely available maps of soil pH at the national scale from Britain (Countryside Survey data from ukso.org). Both these maps were constructed using geostatistical models applied to surveyed $\mathrm{pH}$ data to predict unknown values using wider landscape level datasets, using information such as land cover, parent material, climate etc. Maps were downloaded and rasterized where necessary, prior to extracting of $\mathrm{pH}$ values based on the GB survey coordinates.

Using the detailed $1 \mathrm{~km}$ resolution SoilGrids soil $\mathrm{pH}$ map offered some small improvements in predicting the national scale bacterial data $\left(\mathrm{RMSE}=0.39, R^{2}=0.36\right.$ ) particularly with respect to the acidic habitat scores (Figure 6b). However the predictions 
again were focused around the mean, and extreme scores were not particularly well estimated. It was notable that in inspecting the range of soil $\mathrm{pH}$ values predicted across the UK and comparing with known UK level data that the extreme values were particularly underestimated in the SoilGrids predictions (e.g predictions of $\mathrm{pH} 4$ or $\mathrm{pH} 8$ soils were over or underestimated respectively). Possible explanations could be related to i) difference in $\mathrm{pH}$ determination between the Countryside survey and EU wide LUCAS datasets; ii) undersampling of certain habitats at the EU scale; and iii) geo-statistical artefacts. It is impossible to entirely discount (i) as comparable samples are not available from both surveys, but a cursory inspection of the range of $\mathrm{pH}$ values for both datasets indicated there were no systemic differences in the range of $\mathrm{pH}$ measurements. With respect to ii) as already discussed, part of the reason for the poor fit on the negative side of the interpolated map is the lack of upland areas sampled in the Lucas survey - meaning the predicted $\mathrm{pH}$ for under sampled upland areas such as in Scotland would be higher than in reality. Whilst the SoilGrids predictions utilise global soil $\mathrm{pH}$ data in the model, the LUCAS dataset is also a large contributory dataset which could have a significant influence on the predictions. Finally with respect to geostatistical artefacts (iii), the predictive maps of $\mathrm{pH}$ provide a mean prediction based on a global model, which will always under or overestimate the higher or lower extremities of the $\mathrm{pH}$ range respectively. This could explain why the full range of NMDS1 scores was not adequately reflected in the model predictions.

The $1 \mathrm{~km}$ resolution national scale $\mathrm{pH}$ map performed considerably better in predicting the range of community scores across the Britain (Figure 6c), with better coverage of the extreme ends of the scale, and a much better fit overall (RMSE $\left.=0.31, R^{2}=0.60\right)$. However the entire gradient of scores was not well reflected, since here the predictive map was calculated based on modelled relationships between soil $\mathrm{pH}$ and categorical variables denoting land cover, along with continuous variables related to parent material. Therefore only a limited number of predicted $\mathrm{pH}$ categories are available in this map, constrained by the number of 
land cover classes. Again we observed larger predictive error for lower $\mathrm{pH}$ soil communities, which could relate to potentially weaker relationships between $\mathrm{pH}$ and available land cover classes in these habitats, or less influence of parent material in these generally more organic soils. Another possible reason for the larger relative error for lower scoring communities form acidic habitats could relate to landscape patchiness and the resolution of the maps. For instance, intensively managed parcels of land in the Britain are likely to comprise areas of greater than $1 \mathrm{~km}^{2}$ which is the scale of the UKSO pH map. Human intensified landscapes will typically be more homogenous and of approximately neutral soil $\mathrm{pH}$ to favour plant production (either "naturally" or agriculturally driven). This enhances the probability that a mean value per $\mathrm{km}^{2}$ will reflect a $\mathrm{pH}$ measurement at any given point within that square. Conversely, marginal $1 \mathrm{~km}^{2}$ land patches unfavourable for intensive agriculture will have a greater variety of habitats and so the predictive accuracy with respect to point measures is likely to be reduced.

\section{Conclusions}

This study characterised bacterial biodiversity and explored environmental correlates in a range of soils sampled across continental Europe. In agreement with previous global studies land use, climate and soil abiotic properties were strongly associated with changes in bacterial communities, with soil $\mathrm{pH}$ being the best single correlate. Ultimately these findings point to the general conclusion that broad characteristics of soil bacterial communities can be considered as a dependent soil state variable related to other soil properties (and to some extent human land use); which are ultimately controlled by the independent soil forming factors of climate, relief, parent material, and time (Jenny, 1941). These relationships therefore allow the global prediction of soil bacterial community features over large scales, and we present the first attempt to map bacterial communities across Europe along with a detailed evaluation of the predictions against observed data from national scale surveys of 
one of the EU member states. The map performed adequately in predicting community characteristics (ordination axis scores) albeit for opposing ends of the soil biotic/abiotic gradient, and we further demonstrate how the map can be improved by making use of available predictive maps of soil $\mathrm{pH}$, previously calculated using correlations with georeferenced data on wider soil forming factors. In doing so we highlight the current limitations in soil property maps at different geographic scales, with national scale predictions outperforming global scale maps.

To avoid misinterpretation there are some notable caveats which we must stress with this should be a future ambition of global efforts to characterise soil biodiversity. Our study 
mapping using high resolution remote sensed data. It is possible that similar approaches can be applied to other elements of soil biodiversity, including eukaryotes, given enhanced understanding of controlling environmental parameters. Such knowledge can be gained both by efforts to harmonise existing soil biodiversity datasets, but also by increased eukaryotic sampling in national surveys - a realistic possibility now with the availability of rapid molecular tools for eukaryotes (e.g Ramirez et al, 2014). Finally to conclude, our map identifies that predictions are only as good as the surveyed "real" data used to build models. Predictive accuracy will vary depending on the scale of the surveyed data (model inputs) and the spatial extent of the area we seek to predict. Global predictions at high spatial accuracy should therefore be the ultimate goal, which requires increased efforts to standardise and conduct soil biotic and abiotic surveillance at global scales. These advances will be facilitated by better spatial integration of distributed datasets (e.g. global harmonisation of localised climate, geological, remote sensed land cover, and soil datasets) and continued development and validation of mapping predictions against local surveyed data.

\section{Acknowledgments}

This work was supported by the European Commission within the EcoFINDERS project (FP7264465). The authors are grateful to Tiffanie Régnier for technical assistance; and we extend our gratitude to the two anonymous reviewers whose valuable insights improved the manuscript considerably.

\section{References}

Bivand, R.S., Pebesma,E.J., and Gómez-Rubio,V. 2008. Applied Spatial Data Analysis with R. Springer, ISBN: 978-0-387-78170-9

I.R. Booth. 1985. Regulation of cytoplasmic pH in bacteria. Microbiol. Rev. 49: 359-378 
Bru, D., Ramette, A., Saby, N. P. A., Dequiedt, S., Ranjard, L., Jolivet, C., Arrouays. D., 437 Philippot, L. (2011). Determinants of the distribution of nitrogen-cycling microbial communities at the landscape scale. ISME J. 5: 532-542.

Chapman, D. S., Purse, B. V. 2011. Community versus single-species distribution models for British plants. J. Biogeog. 38: 1524-1535.

Cho, J.C., Tiedje, J.M. 2000 Biogeography and degree of endemicity of fluorescent Pseudomonas strains in soil. Appl Environ Microbiol. 66: 5448-56.

Comerford, N.B., Franzluebbers, A.J., Stromberger, M.E., Morris, L., Markewitz, D., Moore, R. 2013. Assessment and Evaluation of Soil Ecosystem Services. Soil Horizons, 54

Dequiedt, S., Saby, N.P.A., Lelievre, M., Jolivet, C., Thioulouse, J., et al. 2011. Biogeographical patterns of soil molecular microbial biomass as influenced by soil characteristics and management. Glob Ecol Biogeogr 20: 641-652.

Dequiedt, S., Thioulouse, J., Jolivet, C., Saby, N. P.A., Lelievre, M., Maron, P.-A., Martin, M. P., Prévost-Bouré, N. C., Toutain, B., Arrouays, D., Lemanceau, P. and Ranjard, L. (2009), Biogeographical patterns of soil bacterial communities. Env. Microbiol. Rep., 1: 251-255.

Elith, J., Graham, C.H., Anderson, R.P. et al. 2006. Novel methods improve prediction of species' distributions from occurrence data. Ecography, 29, 129-151.

Elton, C.S. 1927. Animal Ecology. University of Chicago Press, Chicago, IL.

Fierer N., Jackson, R.B. 2006. The diversity and biogeography of soil bacterial communities. Proc Natl Acad Sci U S A 103: 626-631. Fierer, N., Leff, J.W., Adams, B.J., Nielsen, U.N., Bates, S.T., Lauber, C.L., Owens, S., Gilbert, J.A., Wall, D.H. and Caporaso, J.G. 2012. Cross-biome metagenomic analyses of soil 458 microbial communities and their functional attributes. Proc. Natl. Acad. Sci. U. S. A. 109: 459 $21390-21395$ 
460

461

462

463

464

465

466

467

468

469

470

471

472

473

474

475

476

477

478

479

480

481

482

483

Fierer, N., J. Ladau, J.C. Clemente, J.W. Leff, S.M. Owens, K.S. Pollard, R. Knight, J.A. Gilbert, R.L. McCulley. 2013. Reconstructing the Microbial Diversity and Function of PreAgricultural Tallgrass Prairie Soils in the United States. Science, 342: 621-624.

Griffiths, R. I., Thomson, B. C., James, P., Bell, T., Bailey, M.J., Whiteley. A. S. 2011. The bacterial biogeography of British soils. Env. Microbiol. 13:1642-1654.

Hengl, T., de Jesus J.M., MacMillan, R.A., Batjes, N.H., Heuvelink, G.B.M., et al. 2014. SoilGrids1km - Global Soil Information Based on Automated Mapping. PLoS ONE 9(8): e105992. doi:10.1371/journal.pone.0105992

Henrys, P., Bee, E., Watkins, J., Smith, N., Griffiths, R.I. 2015. Mapping Natural Capital: Optimising the use of national scale datasets. Ecography 38: 632-638

Hirsch, P.R., Mauchline, T.H. \& Clark, I.M. 2010. Culture-independent molecular techniques for soil microbial ecology. Soil Biol. Biochem., 42, 878-887.

Janssen PH, Yates PS, Grinton BE, Taylor PM, Sait M. 2002. Improved Culturability of Soil Bacteria and Isolation in Pure Culture of Novel Members of the Divisions Acidobacteria, Actinobacteria, Proteobacteria, and Verrucomicrobia. Appl Environ Microbiol. 68: 2391-2396. Jenny, H. Factors of soil formation: a system of quantitative pedology. New York : McGrawHill, 1941. ISBN 0-486-68128-9

Lauber, C.L., Hamady, M., Knight, R., Fierer, N. 2009. Pyrosequencing-Based Assessment of Soil pH as a Predictor of Soil Bacterial Community Structure at the Continental Scale. Appl Environ Microbiol 75: 5111-5120.

Lam, N.S. 1983. Spatial Interpolation Methods: A Review. The American Cartographer $10: 129-50$

R Core Team (2014). R: A language and environment for statistical computing. R Foundation for Statistical Computing, Vienna, Austria. URL http://www.R-project.org/. 
Ramirez, K.S., Leff, J.W., Barberán, A., Bates, S.T., Betley, J., Crowther, T.W., Kelly, E.F., et al. Biogeographic patterns in below-ground diversity in New York City's Central Park are similar to those observed globally. Proc. Roy. Soc. B. 2014;281:20141988.

Rousk, J., Bååth, E., Brookes, P.C., Lauber, C.L., Lozupone, C., Caporaso, J.G., Knight, R., Fierer, N. 2010. Soil bacterial and fungal communities across a pH gradient in an arable soil. ISME J. 4:1340-51

Spurgeon, D.J., Keith, A.M., Schmidt, O., Lammertsma, D.R., Faber, J.H. 2013. Land-use and land-management change: relationships with earthworm and fungi communities and soil structural properties. BMC Ecol 13:46. doi:10.1186/1472-6785-13-46

Stone, D., Blomkvist, P., Bohse Hendriksen, N., Bonkowski, M., Bracht Jørgensen, H., Carvalho, F., Dunbar, M.B., Gardi, C., Geisen, S., Griffiths, R., Hug, A.S., Jensen, J., Mendes, S., Morais, P.V., Plassart, P., Römbke, J., Rutgers, M., Schmelz, R. M., Sousa, 527 J.P., Suhadolc, M., Winding, A., Creamer, R.E. 2015. Establishing a Transect for Biodiversity and Ecosystem Function Monitoring Across Europe. App Soil Ecology (this issue)

Thomson B. C., Ostle N. J., McNamara N. P., Oakley S., Whiteley A. S., Bailey M. J., Griffiths, R.I. 2013. Plant soil interactions alter carbon cycling in an upland grassland soil. Front. Microbiol. 4:253. doi : 10.3389/fmicb.2013.00253

Tóth, G., Jones, A., Montanarella, L. (eds.) 2013. LUCAS Topsoil Survey. Methodology, data and results. JRC Technical Reports. Luxembourg. Publications Office of the European Union, EUR26102 - Scientific and Technical Research series - ISSN 1831-9424 (online); ISBN 97892-79-32542-7; doi: 10.2788/97922

Urich T., Lanzén A., Qi J, Huson D.H., Schleper C., Schuster S.C. 2008. Simultaneous Assessment of Soil Microbial Community Structure and Function through Analysis of the Meta-Transcriptome. PLoS ONE 3(6): e2527. doi:10.1371/journal.pone.0002527 
508 Zhou, J., Xia, B., Treves, D. S., Wu, L.-Y., Marsh, T. L., O’Neill, R. V., Palumbo, A.V., Tiedje, 509 J. M. 2002. Spatial and Resource Factors Influencing High Microbial Diversity in Soil. App.

510 Env. Microbiol. 68: 326-334.

511

512

513

514

515

516

517

518

519

520

521

\begin{tabular}{|c|c|c|c|}
\hline Soil Property & $r^{2}$ & $p$ & \\
\hline $\mathrm{pH}$ & 0.9054 & 0.001 & $* * *$ \\
\hline Clay $(\%)$ & 0.4173 & 0.001 & $* * *$ \\
\hline organic C_N_ratio & 0.3596 & 0.001 & $* * *$ \\
\hline Bulk density $(\overline{\mathrm{g}} / \mathrm{cm} 3)$ & 0.3501 & 0.001 & $* * *$ \\
\hline moisture $(\mathrm{ml} / \mathrm{g})$ & 0.2681 & 0.001 & $* * *$ \\
\hline Organic C (\%) & 0.2624 & 0.001 & $* * *$ \\
\hline $\mathrm{WHC}(\mathrm{ml} / \mathrm{g})$ & 0.2521 & 0.001 & $* * *$ \\
\hline C (\%) & 0.2316 & 0.001 & $* * *$ \\
\hline Total C_N ratio & 0.1961 & 0.003 & $* *$ \\
\hline Silt (\%) & 0.1372 & 0.004 & $* *$ \\
\hline$N(\%)$ & 0.1255 & 0.009 & $* *$ \\
\hline Sand (\%) & 0.0405 & 0.202 & \\
\hline
\end{tabular}


Table 1. Relationships between soil microbial community ordination axis scores and soil physicochemical properties. Correlations between the NMDS ordination and environmental variables are denoted by $r^{2}$ values. Significance $(p)$ was determined by 999 permutations.

Figure 1. NMDS ordination of soil bacterial communities sampled across Europe. Soil pH was found to be the best linear fit to the NMDS ordination scores, and is identified in the plots by a colour gradient denoting the $\mathrm{pH}$ for each sample. Centroids are also shown representing the mean score per land use type.

Figure 2. Relationship between soil $\mathrm{pH}$ and bacterial community NMDS first axis ordination scores from the 76 sampled soils. The second-degree polynomial fit is also displayed together with $95 \%$ prediction intervals.

Figure 3. Using the pH-NMDS1 model determined from 76 soils across Europe to predict NMDS1 scores from $>1000$ soil $\mathrm{pH}$ measurements across Britain. The value for the predictions is shown on the $y$ axis, whereas the $x$ axis denotes the actual observed bacterial community scores from the study of Griffiths et al, 2011. The line shows the fitted least squares regression between the observed and predicted values $\left(R^{2}=0.8\right)$.

Figure 4. Interpolated map showing predicted bacterial community ordination scores across EU member states. Colour scale indicates predicted first axis NMDS scores, with negative 
scores indicating acidic soils (bogs, acid grassland, upland woods etc) and positive scores indicating communities from more neutral pH soils (productive grassland, arable etc)

Figure 5. Relationship between NMDS first axis scores for bacterial communities and univariate indices of diversity (line denotes a loess fit). Increases in NMDS scores are generally indicative of an increase in bacterial diversity.

Figure 6. Validating spatially mapped predictions of bacterial NMDS scores against national scale survey data for Britain. In all plots the observed data are the actual community scores reported from over 1000 soils sampled across Great Britain (Griffiths et al 2011). Predicted community scores are based on the modelled relationships between bacterial communities and $\mathrm{pH}$ from the EcoFINDERs transect sampling fitted to different spatial estimates of soil $\mathrm{pH}$ : a) spatial interpolation of community scores predicted from EU wide point data on soil pH (this study); b) geostatistical predictions of topsoil $\mathrm{pH}$ values at the global scale (soilgrids.org, Hengl et al, 2014); c) geostatistical predictions of topsoil pH values at the national scale (ukso.org, and see Henrys et al; 2014). Solid red lines show the fitted least squares regression between the observed and predicted values (with associated $R^{2}$ displayed in the top right of each plot); and dashed lines display loess fits to illustrate deviations from the linear fit. 
Figure 1. NMDS ordination of soil bacterial communities sampled across Europe.

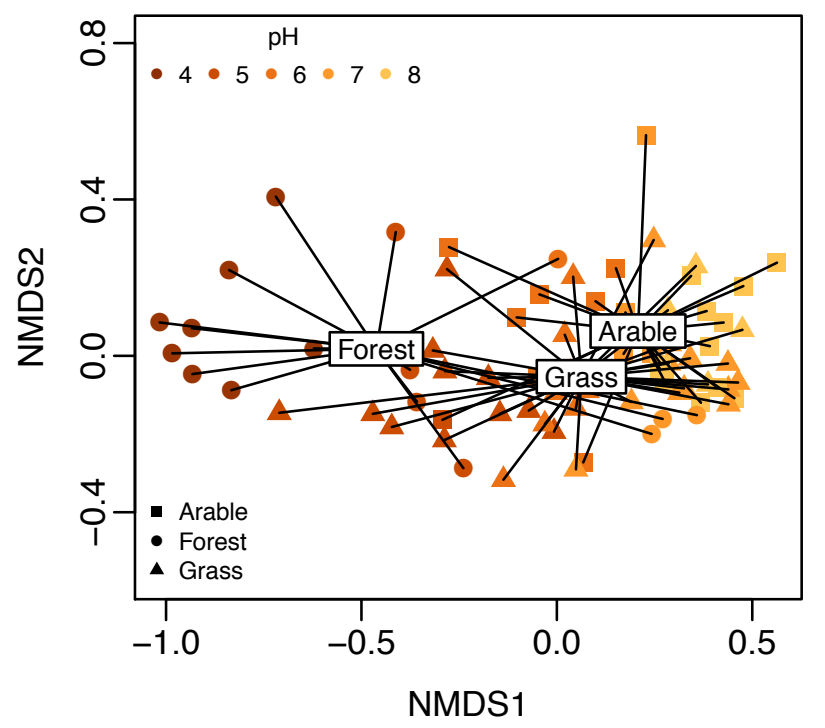


Figure 2. Relationship between soil $\mathrm{pH}$ and bacterial community NMDS first axis ordination scores from the 77 sampled soils.

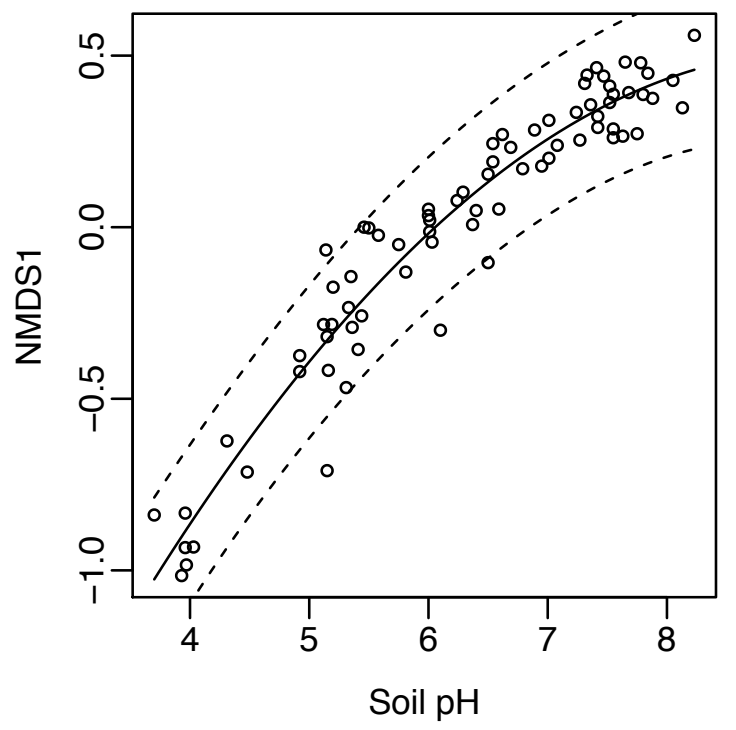


Figure 3. Using the pH-NMDS1 model determined from 77 soils across Europe to predict NMDS1 scores from $>1000$ soil pH measurements across Britain.

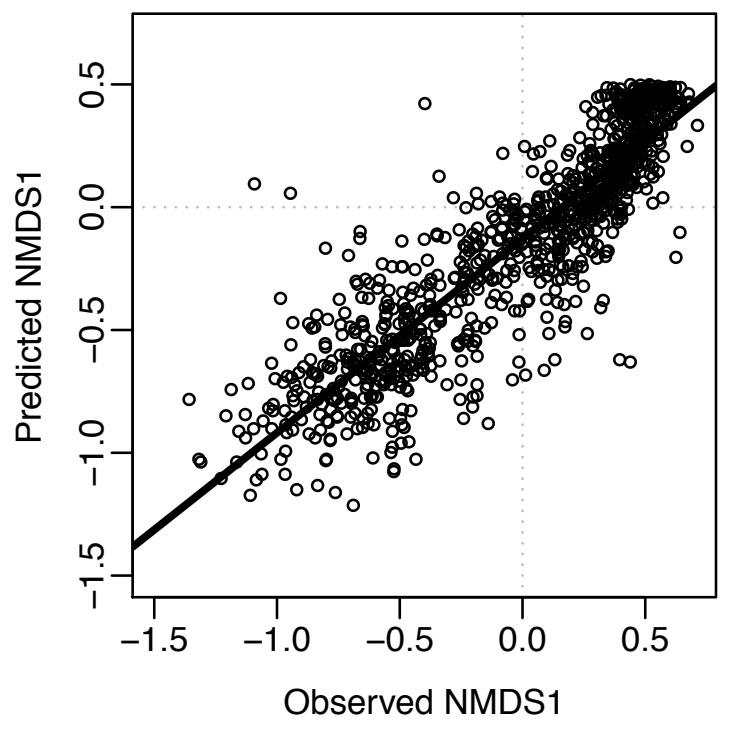


Figure 4. Interpolated map showing predicted bacterial community ordination scores across EU member states.
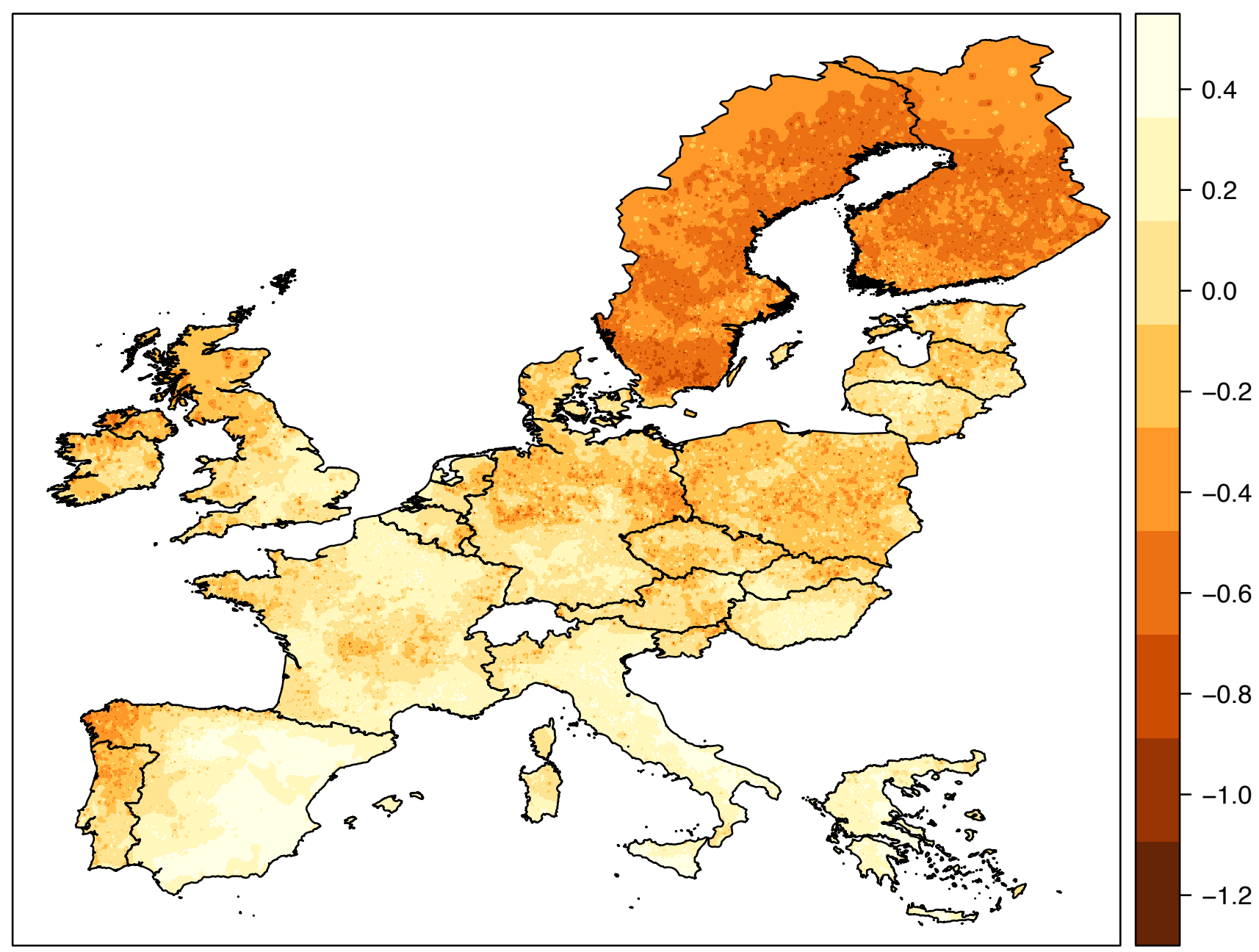
Figure 5. Relationship between NMDS first axis scores for bacterial communities and univariate indices of diversity

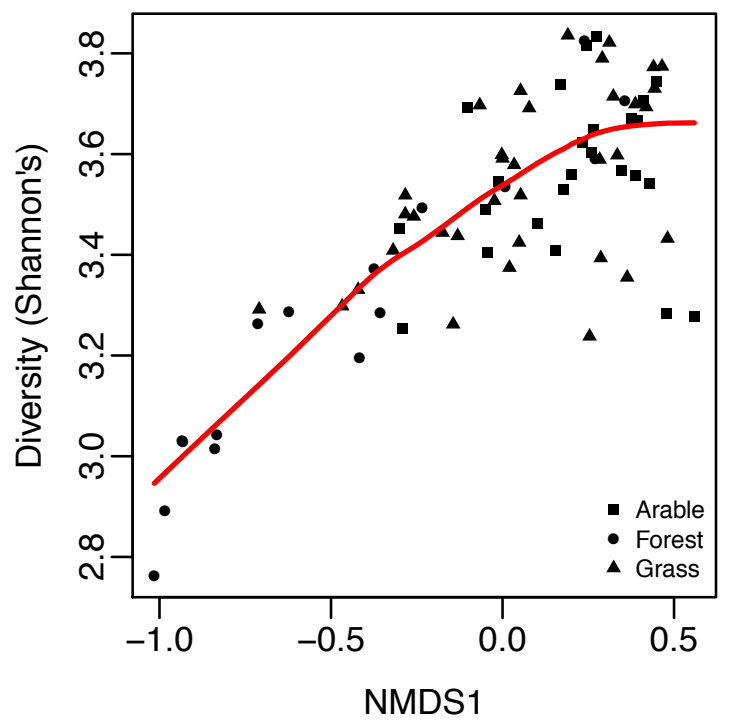


Figure 6. Validating the spatially mapped predictions of NMDS scores against national scale survey data for Britain.

a) Mapped point data (this study)

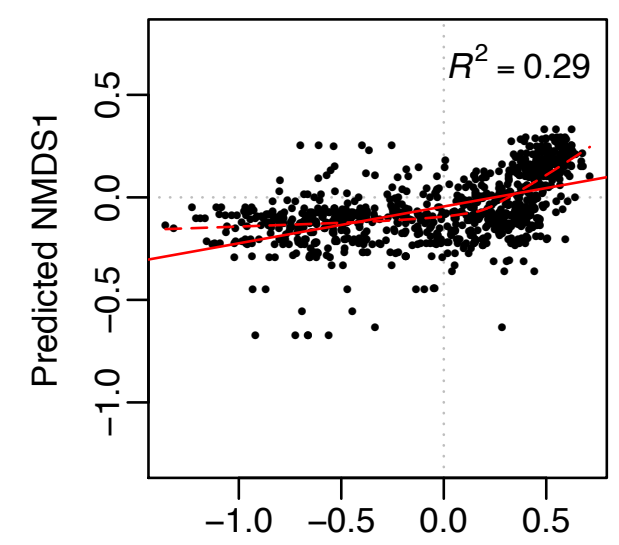

b) Global soil map (SoilGrids)

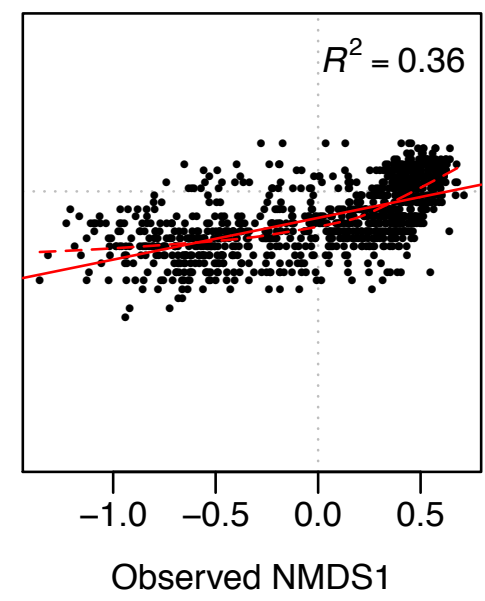

c) UK soil map (UKSO)

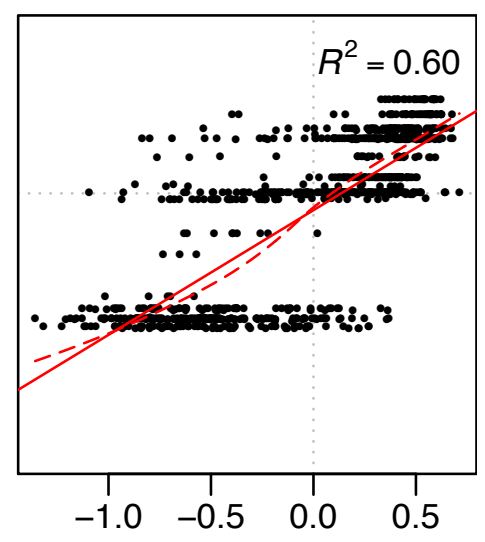

